\title{
The Research and Practice of Making Time Sequence of Urban Road Construction Based on Big Data - Taking Jinan as an Example
}

\author{
Lu Yuan ${ }^{1,}$, , Liu Shicheng ${ }^{2}$, Li Song $^{1}$, Lin Songtao ${ }^{1}$ \\ ${ }^{1}$ Shandong Zhongxing Urban \& Rural Transportation Research Consulting Co. Ltd, Jinan, China \\ ${ }^{2}$ College of Science, Virginia Tech, Blacksburg, the United States
}

Email address:

luyuanhhuc@163.com (Lu Yuan)

*Corresponding author

\section{To cite this article:}

Lu Yuan, Liu Shicheng, Li Song, Lin Songtao. The Research and Practice of Making Time Sequence of Urban Road Construction Based on Big Data - Taking Jinan as an Example. American Journal of Traffic and Transportation Engineering. Vol. 6, No. 5, 2021, pp. 133-138. doi: $10.11648 /$ j.ajtte.20210605.11

Received: August 11, 2021; Accepted: August 26, 2021; Published: September 11, 2021

\begin{abstract}
Urban roads are an important support for promoting urban economic development, and the situation of urban traffic operation especially urban traffic congestion depends on whether the construction of road network is reasonable. With the rapid development of multi-source data, it provides quantitative data support for the scientific compilation of urban road construction plans. Based on urban planning, this paper analyzes the travel characteristics of residents based on mobile phone data, and combines the road congestion data and road speed data, and uses professional traffic models to fully predict the future situation of urban traffic, thereby drawing the necessity of different roads construction, while providing reverse corrections for transportation planning. It proposed a research on urban road construction planning based on multi-source big data, to promote the healthy and sustainable development of road construction and improve the efficiency of the road construction fund. Taking the road construction planning research of Jinan City as an example, construct the transportation model, based on the phone data, congestion data, public transport data, and traffic police bayonet data for verification, it show the applicability of big data technology in urban road construction planning and promotes the practice of big data technology in the transportation field.
\end{abstract}

Keywords: Big Data, Urban Road Construction, Constructing Sequence, Traffic Demand

\section{Introduction}

With the rapid economic development and the rapid progress of urbanization, the contradiction between the limited resources of urban road and the rapid growth of traffic demand has become increasingly prominent. Insufficient urban road supply capacity, coupled with unreasonable road network planning, has led to problems such as traffic congestion and frequent traffic accidents. In order to solve urban traffic problems, it is necessary to improve the road network structure [1] and increase the road network capacity while continuously improving traffic management measures. The roads that have not met the planning standard are uniformly screened according to certain principles and methods, and the construction sequence is arranged in an overall manner, which helps to improve the efficiency of the use of financial funds.

At present, the completion rate of road construction in the downtown area of Jinan is only $51 \%$, and there is a large gap in road construction. This article is guided by the planning road network, focusing on the long-term urban planning and development and the near-term residents' traffic needs. Starting from the road function positioning, current traffic operation conditions and road construction feasibility, this paper studies the time sequence influencing factors of road construction, and uses Jinan West End as a practice. Sort out the unbuilt road network, analyze the traffic demand and the operation of the road network, quantify the necessity of road construction, comprehensively consider the difficulties of demolition, 
etc., scientifically formulate road construction plans, and provide theoretical support for decision makers to improve the road network. The research results can guide urban road construction in Jinan and promote the healthy and sustainable development of the city.

\section{The Analysis of Influence Factors on Urban Road Construction}

Carry out the general survey of the road network of Jinan West Station District, according to the network map, ortho-photo map and field investigation methods. Combined with the planning road, create the road database based on GIS system, and then set up the electronic archives of planning road network without constructing.

\subsection{The Density of Road Network}

Based on the GIS [2], analyze the density of road network [3] in Jinan and make the heat map of road network density. Find out the unbuilt roads in low density area.

\subsection{Traffic Demand}

Based on the phone data, analyze the traffic demand $[4,5]$ in the district especially in peak hour. We use the VISUM software [6] to establish the transport model of Jinan. The result shows that, in the last two years, the trip generation has increased $11.5 \%$ and the trip attraction increased $56 \%$ in morning peak hour. Pick up the roads that can support the tremendous growth of traffic demand needs, especially the outward passageway that can connect the adjacent districts [7]. (Affected by the epidemic, the data in year 2020 does not have reference).

\subsection{District Development and Construction}

According to the land-use planning in the district, the land-using is mainly for living, shopping, and educating etc. Find out the unbuilt roads to guide the land leasing.

\subsection{Traffic Congestion}

According to the analysis of traffic situation in the last two years, the traffic congestion delay index has raised from 1.62 to 1.71 , and the speed has declined from 30.9 to $27.4 \mathrm{~km} / \mathrm{h}$. The traffic condition is deteriorating and other diversion roads should be constructed to alleviate the traffic congestion.

\subsection{Road Land Property}

Analyze the land use of road area, including basic farmland preservation area, the demolition and so on, evaluate the construction condition of the unbuilt roads.

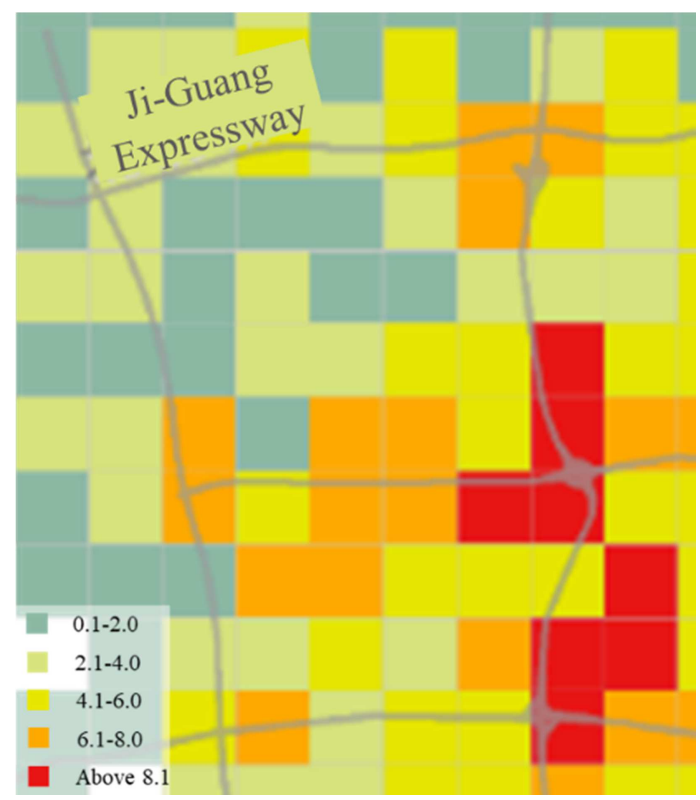

Figure 1. The Road Density of the research area (unit: $\left.\mathrm{km} / \mathrm{km}^{2}\right)$.

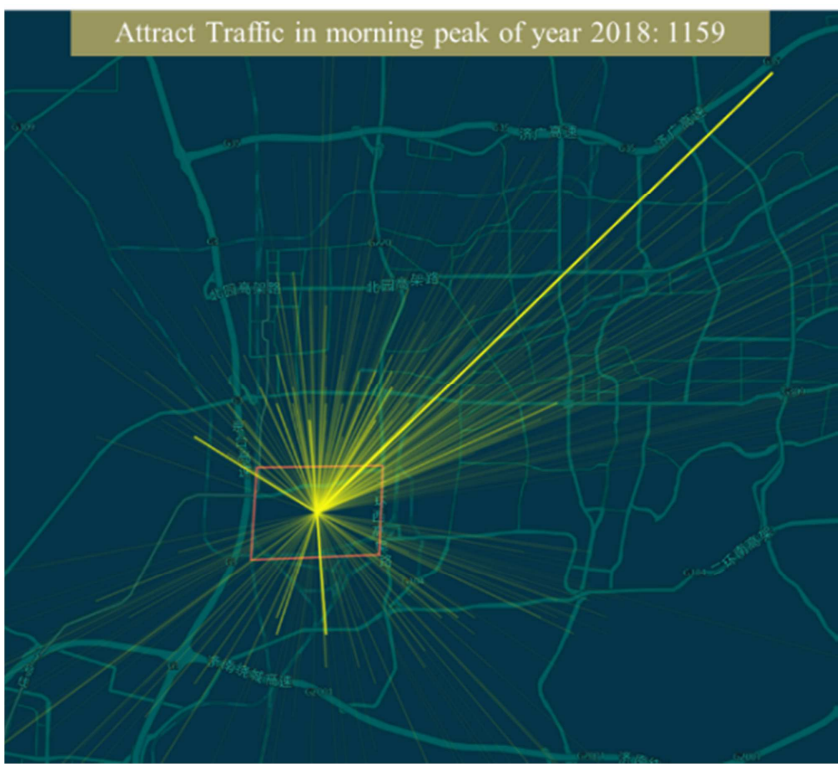

Figure 2. The traffic OD in morning peak hour in year 2018. 

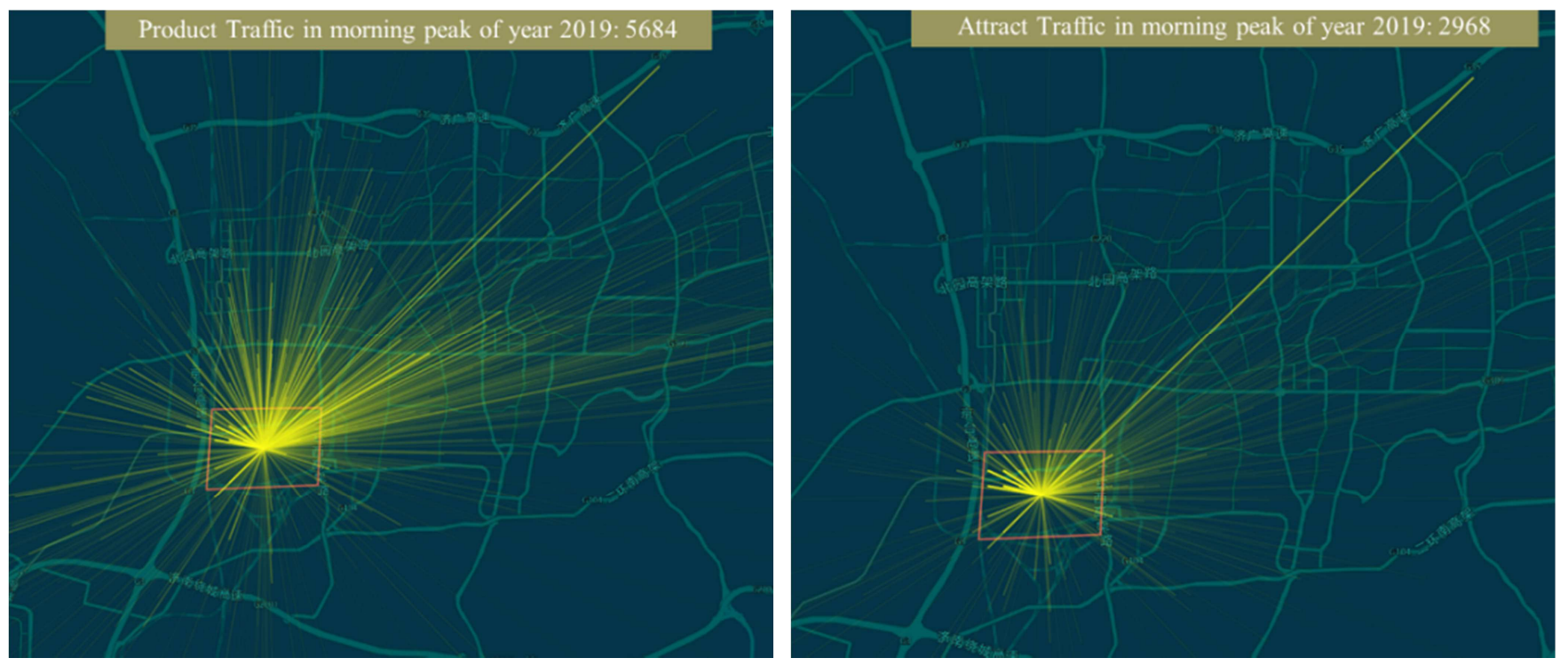

Figure 3. The traffic OD in morning peak hour in year 2019.

\section{The Research Practice in Jinan West Station District}

\subsection{The Statistics of Unbuilt Roads}

The statistic result shows that there are about $148.1 \mathrm{~km}$ existing road and $48.7 \mathrm{~km}$ unbuilt road, including arterial roads $1.87 \mathrm{~km}$, sub-arterial roads $16.45 \mathrm{~km}$ and branch roads $30.35 \mathrm{~km}$.

\subsection{The Traffic Demand Analysis}

Built the traffic zone based on the land use and development, create the OD matrix based on the phone data and the household survey data, and use the police bayonet data for checking. At last build the traffic model to analyze the traffic volume [8] variation under different road construction.

Based on the current road network, if no other roads are to built, some roads will burden more traffic volume. The traffic volume will increase $1000 \mathrm{pcu} / \mathrm{h}$ of Beiyuan Street, Qizhou road (from south to north), Yantai road, Lashanhe West road (to the south of Yantai lu), Zibo road. The traffic volume will increase more than $2000 \mathrm{pcu} / \mathrm{h}$ in the Beiyuan express way and Erhuan West express way.

According to the traffic model, it shows sharing volume under different roads after constructing [9]. The primary diversion roads are Zibo road, Weifang road, Liaocheng road, Zaozhuang road, Dezhou road and Laiwu road. The roads that turns better are Qizhou road, Lashanhe West road, Xiaoqinghe North road, Xiaoqinghe South road, Qingyuan road, Xinfusi road and some branch roads in Zhangzhuang district.

\subsection{The Diversion Roads for Alleviating Congestion}

According to the traffic congestion data from internet map in the district, Laiwu road, Qingyuan Road, Binzhou road,
Lashanhe East road, Zibo road and Weihua West road are in bad condition. The diversion roads are listed as follows.

\subsubsection{Diversion Roads for Laiwu Road}

The roads that can help ease the congestion of Laiwu road are listed as follows [10]: Zibo road (from Yantai road to Jingshi Road), Zaozhuang road (from Binzhou road to Erhuan west road), Yantai road (hasn't meet the plan standard), Dongying road (hasn't meet the plan standard).

\subsubsection{Diversion Roads for Qingyuan Road and Binzhou Road}

The roads that can help ease the congestion of Qingyuan road and Binzhou road are listed as follows: Zibo road (from Qinghe South road to Qingyuan Road), Weifang road (from Qinghe South road to Qingyuan Road), Dezhou road (from Binzhou road to Erhuan West road).

\subsubsection{Diversion Roads for Lashanhe East Road and Zibo Road (to the North of Yantai Road)}

The roads that can help ease the congestion [11] of Lashanhe East road and Zibo road (to the north of Yantai road) are Zibo road (from Yantai road to Jingshi road) and Zongzhi $8^{\text {th }}$ road.

\subsubsection{Diversion Roads for Kaichuang Road and Taian Road}

The roads that can help ease the congestion of Kaichuang road and Taian road are Taian road (the south section) and Mengxiang road.

\subsubsection{Diversion Roads for Weihua West Road}

The roads that can help ease the congestion of Weihua West road is Kelangshan North road.

\subsection{The land Development and Land Leasing}

According to the land development and land leasing materials plans, comb the accompany roads for under construction lands [12]. Road names are listed in appendix. 

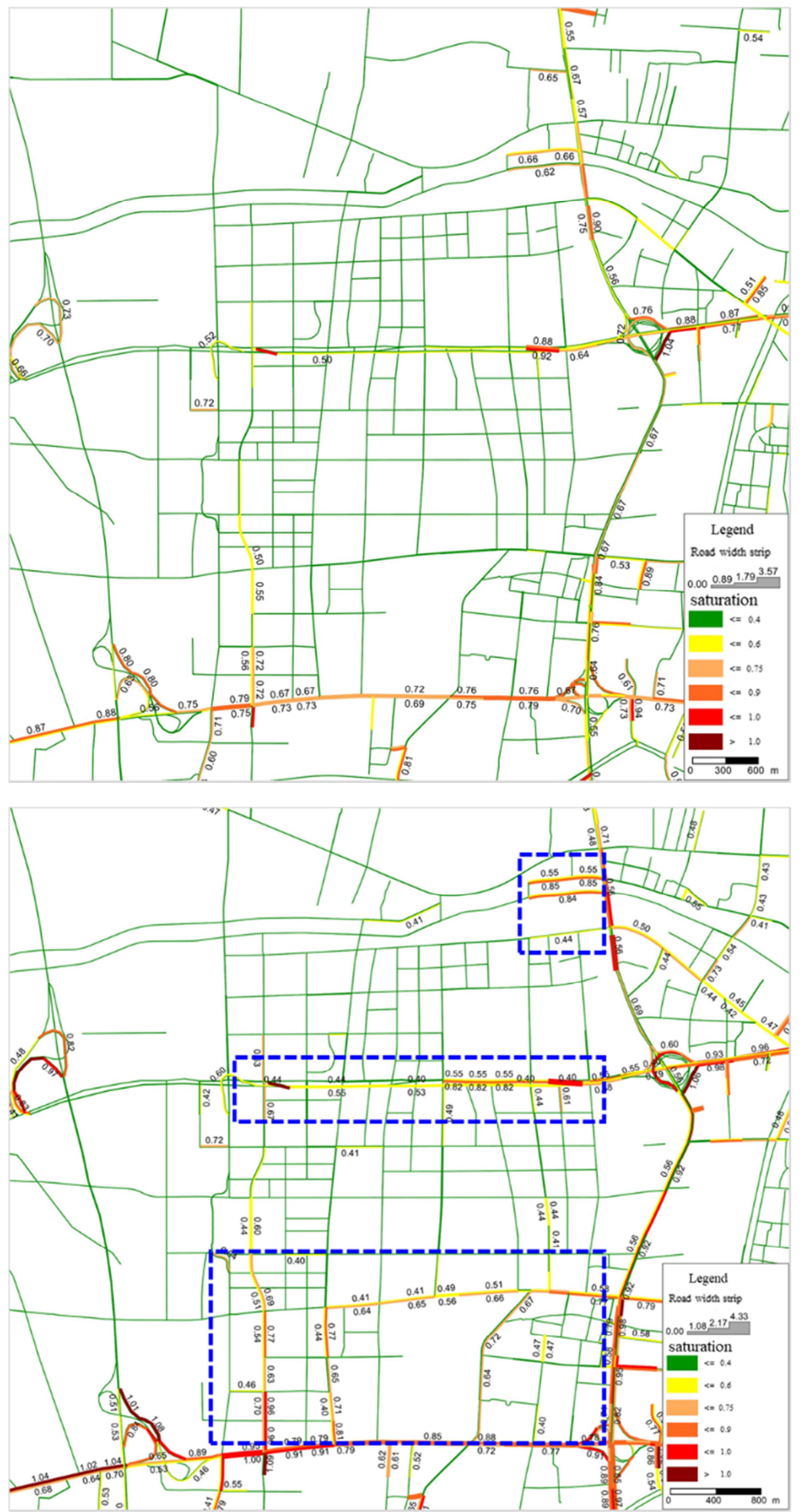

Figure 4. The comparison of Road saturation between current and future traffic demand based on the same road net. 

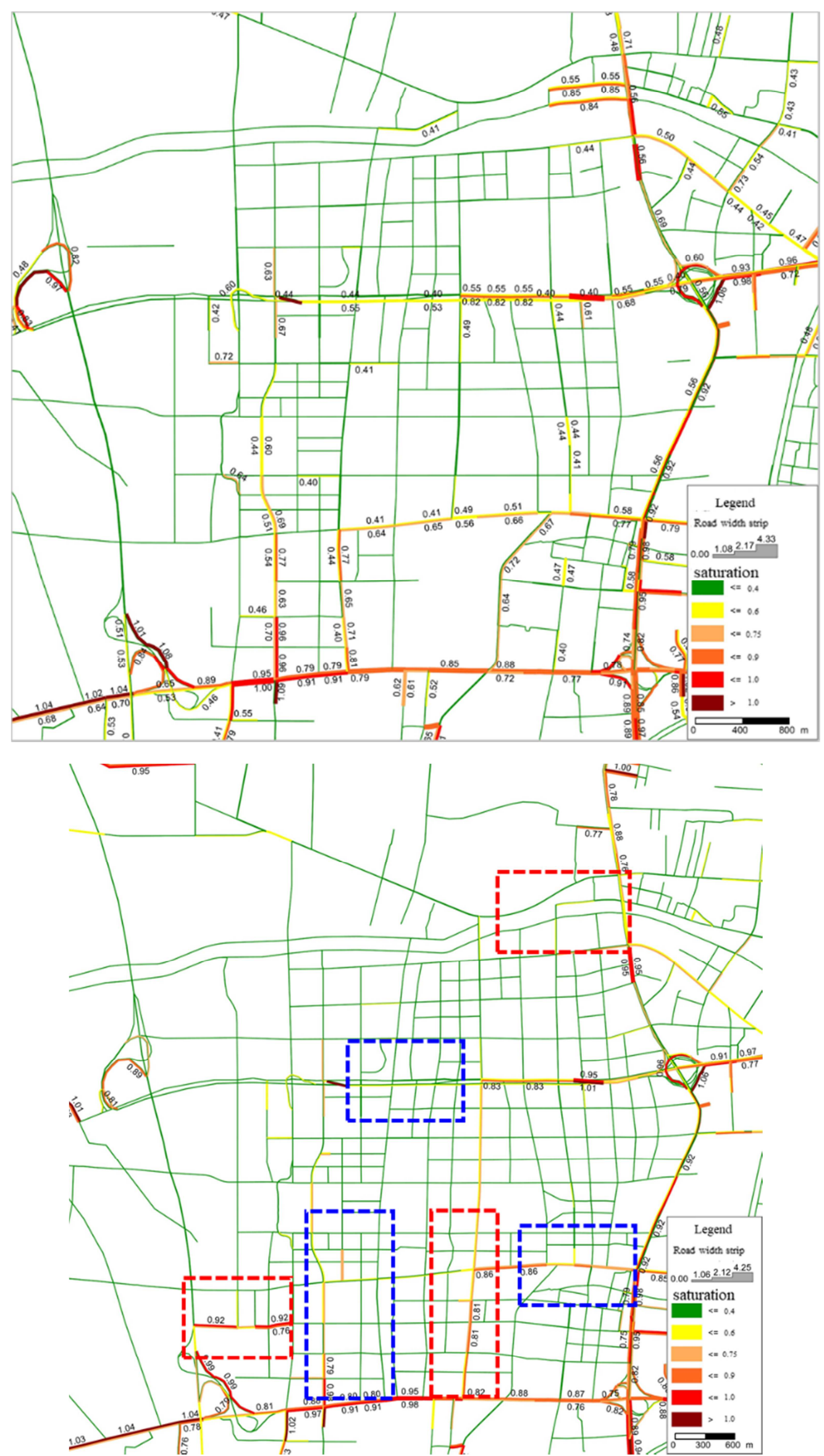

Figure 5. The comparison of Road saturation between current and future roads net based on the same traffic demand. 


\subsection{The Time Sequence for Road Constructing}

Considering the traffic demand, the diversion roads for alleviating congestion, the accompany roads for area development to make the constructing sequence of roads, ranking by necessity [13]. And then evaluate the implementation of the road to draw up the final construction plan.

\section{Conclusion}

This paper considers kinds of influence factors [14] about urban road construction, including the density of road network, the traffic demand, the district development, the traffic congestion and constructing limiting conditions to help make time series of urban road construction. The field practice in Jinan West Station District show that the method [15] provided in this paper has strong operability, and can be extended to the whole city range and provide support for decision makers and managers.

\section{References}

[1] WANG Liliang. Study on Sequencing of the Urban Roads Construction based on complex network [D]. Chongqing Jiaotong University, 2014.

[2] ZHANG Zuo, TAN Shukui, TANG Wenwu. A GIS-based Spatial Analysis of Housing Price and Road Density in Proximity to Urban Lakes in Wuhan City, China [J]. Chinese Geographical Science, 2015, 25 (06): 775-790.

[3] LI Yan, WANG pengfei. Spatial Differentiation Characteristic of Road Density Based on GIS: Acase Study of Shijiazhuang City [J]. Journal of Hebei Normal University of Science \& Technology Vol. 32 No. 4 December, 2018.

[4] Guo Miao, Zhao Xiaohua, Yao Ying, Yan Pengwei, Su Yuelong, Bi Chaofan, Wu Dayong. A study of freeway crash risk prediction and interpretation based on risky driving behavior and traffic flow data [J]. Accident Analysis and Prevention, 2021, 160.

[5] Zhang Zikai, Li Yidong, Song Haifeng, Dong Hairong. Multiple dynamic graph based traffic speed prediction method [J]. Neurocomputing, 2021, 461.
[6] Bartłomiej PIĄTKOWSKI, Michał MACIEJEWSKI. Comparison of traffic assignment in VISUM and transport simulation in MATSim [J]. Transport Problems, 2013, 8 (2).

[7] Yin Ling, Lin Nan, Zhao Zhiyuan. Mining Daily Activity Chains from Large-Scale Mobile Phone Location Data. [J]. Cities (London, England), 2021, 109.

[8] Junqing Shi, Yongju Hu, Sulan Li, Zhiqiang Li, Xinhuan Zhang, Chengyuan Mao. Simulation and analysis of road construction traffic flow in urban road networks [J]. Advances in Mechanical Engineering, 2015, 7 (11).

[9] Eul-Bum Lee, David Thomas, Loren Bloomberg. Planning Urban Highway Reconstruction with Traffic Demand Affected by Construction Schedule [J]. Journal of Transportation Engineering, 2005, 131 (10).

[10] Zhao Wang, Lei Chen. Research on the Impact of Road Construction on Traffic Congestion [P]. Proceedings of the 2016 International Conference on Management Science and Management Innovation, 2016.

[11] Wu Jianhui, Huang Zhongxiang, Li Wu, Wu Jianhui, Peng Xin, Zhang Sheng. Robustness Optimization of Sequence Decision in Urban Road Construction [J]. Computer Science, Vol. 45 No. 4 Apr, 2018.

[12] Wang Pengfei, Liu Peng, Wang Chenlan, Wang Ange, Guan Hongzhi, Li Song, Xia Xiaojing. Optimal dynamic investment allocation on construction of intelligent transportation infrastructure and road maintenance with environmental costs [J]. Journal of Cleaner Production, 2021, 284.

[13] Kim B J, Kim W, Song B H. Sequencing and scheduling highway network expansion using a discrete network design model [J]. Annals of Regional Science, 2008, 42 (3): 621-642.

[14] YE Q, UKKUSURI S V. Resilience as an Objective in the Optimal Reconstruction Sequence for Transportation Networks [J]. Journal of Transportation Safety \& Security, 2015, 7 (1): 91-105.

[15] Janackovic G L, Savic S M, Stankovic M S. Selection and ranking of occupational safety indicators based on fuzzy AHP: A case study in road construction companies [J]. South African Journal of Industrial Engineering, 2013, 24 (3). 